\title{
Habermas e Foucault: a busca do discurso pós-epistemológico sobre a ciência
}

\author{
Habermas y Foucault: La búsqueda del discurso post-epistemológico sobre la ciencia
}

Habermas and Foucault: the search for a post-epistemological discourse about science

\author{
Maria Nelida GonZÁLEZ DE GómEZ \\ Programa de Pós-graduação em Ciência da Informação- Universidade Federal Fluminense - \\ UFF. Rua Tiradentes, 148 - Ingá - Niterói - RJ - BRASIL. marianelidagomez@gmail.com
}

\section{Resumen}

Se revisita el pensamiento de dos pensadores que representan dos de las grandes tradiciones europeas de pensamiento, Jürgen Habermas y Michel Foucault, con el fin de indagar el lugar y dirección de las investigaciones actuales sobre el discurso científico. Ambos comparten la búsqueda de una elaboración personal que transcienda las constricciones de las ontologías y jurisdicciones convencionales. Para ello, desarrollaron un nivel metateórico de reflexión que, por su alto valor especulativo, es más probable que mantenga su actualidad en el futuro.

Palabras clave: Habermas, Jünger. Foucault, Michel. Filosofía de la ciencia. Discurso científico. Significado. Verdad. Verificación.

\section{Sobre a direção do perguntar}

De maneira simplificada, mas frequente, nos estudos da filosofia, fala-se de três categorias ou princípios paradigmáticos que teriam agregado, em períodos mais ou menos extensos, as grandes constelações teóricas do pensamento ocidental, indicando a direção predominante do perguntar. Podem ser enunciados como grandes orientações paradigmáticas, numa sequência não sem falhas nem justaposições, um princípio ontológico, um princípio gnosiológico e um princípio focado na linguagem (González de Gomez, 1993). Esse esquema e categorização de princípios paradigmáticos, parece que hoje seria inadequado ou insuficiente para organizar uma ação investigativa.

Por um lado, alguns temas e questões possuem excedentes de relevância que os projetam além de qualquer categoria disciplinar, institucional ou linguística. Por outro lado, os processos de autocompreensão humana requerem novos espaços de esclarecimento e concertação de interesses, dando lugar a grandes conferências nacionais e internacionais, e a documentos chancelados por governos, instituições internacionais, organizações políticas e corporativas e outras instâncias expressivas da sociedade civil.

\begin{abstract}
Two thinkers who represent two major European traditions, Jürgen Habermas y Michel Foucault, are revisited to inquire on the locus and direction of contemporary research into the scientific discourse. They both share their pursuit of a personal elaboration of these questions beyond the constraints of conventional ontologies and jurisdictions. For this purpose, they built a meta-theoretical level of reflection that, being speculative, will probably keep its topicality in the future.
\end{abstract}

Keywords: Habermas, Jünger. Foucault, Michel. Philosophy of science. Scientific discourse. Verification.Meaning. Truth.

A reversão da "virada linguística" e o ressurgimento e expansão de abordagens da metafísica e da ontologia, na filosofia e em novos domínios investigativos (como a biotecnologia), é um caso exemplar desses novos indicadores de relevância. E um dos centros desse revigoramento, se bem não o único, encontra-se justamente naquelas áreas do conhecimento que lideravam a busca de metodologias de substituição: a filosofia analítica, a filosofia da matemática e da física. (Smith, 2003; Simons, 2004; Floridi, 2004; Viveiro de Castro, 2012, entre outros). Kohn (2015) a partir do que denomina ontological antropology, considera que a antropologia sociocultural, que acompanhara o movimento humanístico da virada linguística, não teria já recursos conceituais e metodológicos suficientes para lidar com as questões do Antropoceno, no qual a existência humana está tão emaranhada com os seres não humanos e com a própria Terra, que seria impossível falar de ética e política como se foram problemas exclusivamente do homem.

No cenário de tais questões e demandas, aconteceria uma dupla mobilização de ideias e pessoas: Em primeiro lugar, observa-se o surgimento, cada vez mais frequente, de grandes conferencias e documentos coletivos onde são levantadas demandas de validade, sob o pano de 
fundo de processos deliberativos, avaliativos $\mathrm{e}$ de negociação de interesses, concernentes a temas que são de interesse ético e político, como o clima, a saúde, a biodiversidade; um exemplo seria a Conferência do Clima, de Paris, 2015. As alertas sobre as marcas geológicas deixadas pelo homem sobre a terra, e a emergência acelerada de uma nova era, o Antropoceno, é novamente um bom exemplo desse discurso transdisciplinar, ético e político, com inflexões normativas, que se dissemina por diversos meios, duplicados e ampliados pela Internet, como por exemplo, artigos da revista Science, programas e crônicas da BBC, e literatura de diversas áreas do conhecimento (Steffen et al., 2015; Falcon-Lang, 2011; Latour, 2014).

Para Capurro (2004), a proliferação dessas instancias intermediárias entre a ciência, o Estado, a sociedade e o mercado, estaria deslocando os debates sobre normas e valores dos contextos especializados da academia para a esfera política e jurídica. Conforme Capurro, "Em vez da ética e da política pública, encontramos a ética na política pública" (Capurro, 2004, tradução nossa).

$O$ redimensionamento de abordagens e questões, parece afetar, de modo mais evidente, não os discursos das ciências, nelas mesmas (os que de fato, também estão em transformação), mas os discursos que envolvem, entre outros temas, a ciência, como provedora de recursos de justificação de qualidade.

Se as estruturas clássicas de avaliação epistêmica da pesquisa são estabelecidas em fóruns disciplinares e especializados (revisão por pares), surgem agora exigências de novas formas públicas de justificação (Jasanoff, 1987, p. 226).

Frente a esse panorama, começamos a perguntar-nos pela construção de um plano meta-teórico e meta-normativo, onde a questão da ciência e seus contextos avaliativos, estariam passando pelo crivo das novas demandas transdisciplinares, éticas e políticas de validade e justificação.

Consideramos assim que seria pertinente a reconstrução de duas concepções metateóricas de Habermas e Foucault que, se durante anos se estudaram dissociados, hoje têm autores que, como Honneth (2009), os reúnem enquanto exponentes das teorias críticas. Essas construções metateóricas, que vão a operar como antecipações da virada pós-epistemológica da discursividade científica, são a teoria do Discurso de Habermas e os regimes de veridição, de Foucault.

\section{Habermas: o Discurso e o déficit de legitimação}

Habermas tem afirmado que seria próprio das sociedades modernas um déficit constitutivo de legitimação enquanto composição de complexos interacionais sem garantias metasociais (Habermas, 1997, p. 45, grifo nosso), indicando que sua problematização de normas, valores e direitos buscaria entender, no nascedouro, uma brecha originária das modernas sociedades ocidentais.

Sua teoria da ação comunicativa parte da hipótese de que, no contexto das interações comunicativas da vida cotidiana, existe uma reserva potencial de recursos normativos e valorativos, capazes de fornecer critérios para a crítica e, quiçá, subsídios para novas utopias democráticas.

A ação comunicativa é uma ação social que se caracteriza por realizar "atos de fala orientados ao entendimento mútuo", sendo que a explicação de cunho linguístico e semântico dos atos de fala (Searle, 1985), passará por transformações rigorosas, por seu deslocamento aos contextos vinculantes e normativos de uma ação social.

Nessa direção, procedemos à releitura de algumas de suas teses mais conhecidas, a saber: o papel heurístico outorgado à abordagem pragmática da linguagem; a passagem da ação comunicativa cotidiana ao plano reflexivo e deliberativo que denomina discursos (Diskurs) (I) junto a uma breve referência a seus esforços por projetar um movimento progressivo da razão comunicativa, na esperança de ancorar, nas matrizes meta-normativas dos discursos e seus fóruns argumentativos, uma dinâmica híbrida e recursiva entre os sistemas de conhecimento e as esferas normativas da vida social.

Somos ciente de ter deixado ao mesmo tempo, muitas outras importantes questões e teses.

\subsection{Da semântica formal à pragmática formal}

A filosofia analítica que, em suas expressões contemporâneas, busca a renovação de suas heurísticas e conceitos nos repositórios linguísticos e metodológicos da Ontologia (Smith, 2003), no início do século $X X$, dava início à virada linguística, com o objetivo de desenvolver uma linguagem ideal para a ciência, que a resgataria de vez de toda ilusão metafísica.

As condições linguísticas ideais precediam ou mesmo substituíam as condições epistêmicas de acesso ao real e ao conhecimento verdadeiro, subordinado aos modelos lógicos os procedimentos empíricos de verificação. Nesse cenário, a epistemologia perdia suas funções normativas, 
restando-Ihe a tarefa terapeutica da análise lógica dos enunciados e argumentos científicos.

O mais relevante, desde o início da virada linguística, seria a relação que se estabelece entre verdade e significado, numa série de abordagens que reuniam aportes da lógica, da linguistica e da filosofia da linguagem. Em suas primeiras versões, aquela relação era expressada em uma de suas fórmulas mais conhecidas: O sentido de uma proposição é o método de sua verificação.

Habermas encontrará na pragmática a orientação investigativa mais promissora, seja evitando as "falacias abstrativas" da semantica formal, seja como ferramenta heurística para develar novas camadas de sentido na reconstrução da ação social: a) a asbtração semântica propriamente dita consistiria em disociar o conteúdo proposicional dos enunciados dos contextos de sua enunciação; b)a abstração cognitivista, consistiria em reduzir o significado ao modo de significação de proposições assertóricas; c) a abstração objetivista, elimina o papel dos falantes e ouvintes na geração dos conhecimentos, de modo que as condições de verdade são aquelas que podem ser aferidas pela lógica ou a experimentação, pela observação independente de contexto (ver Maeve Cooke, 1998)

De fato, algumas versões da pragmática apresentavam também reduções cognitivistas, fazendo coincidir as condições de validade com a verdade proposicional (2) Habermas procura superar esses limites, deslocando as questões de significado e validade, de seu locus inicial nos atos de fala, ao contexto de uma ação social. $O$ modelo do ato de fala seria subsumido na matriz paradigmática da ação social comunicativa, por duas operações principais: atrelando ao princípio modalizador do enunciar, ou princípio ilocucionario, um sistema ampliado de demandas de validade, e colocando em evidencia o efeito vinculante do compromisso ilocucionário, na coordenação de ações intersubjetivas (efeito de acoplamento entre ego-alter).

Tratava-se de conceber uma nova matriz epistemica para a sociologia e a filosofia social, tal que for possivel a) considerar a produção subjetiva de sentido como um dado sociológico primitivo ou irreductivel; b) substituir o paradigma dualista da relação sujeito-objeto por um modelo comunicativo da intersubjetividade, fazendo da geração compartilhada de significado um componente prioritário do ser social; c) incorporar e transformar a teoria dos atos de fala numa teoria do agir comunicativo (Cooke, 2011).

Como resultado da subsunção do ato de fala numa ação social comunicativa, seria resgatado o potencial normativo que vai alavancar as demandas de legitimação da ordem social, assim como sua teoria crítica da sociedade atual ( $\mathrm{Ha}-$ bermas, 1988; Cooke,1998, 2011; Benhabib,1985, 1986)

A proposta básica de Habermas consiste em sustentar que entendemos o significado de um ato enunciativo quando conhecemos o que o faz aceitável, e conhecemos o que faz um ato enunciativo aceitável quando conhecemos as razões que o o falante poderia propor ao ouvinte, na busca de entendimento e da aceitação justificada das demandas de validade contestadas. Essa potencia de validação providenciaria recursos de legitimação, dentro de certas condições. Primeiro, pela condição pós-metafísica, esse potencial deve ser imanente as formações sociais em que se constitue; segundo, pelo grau de generalização requerida, não deve ficar limitado pelos contextos singulares de sua formação.

Por isso, Habermas não buscará assentar, no vínculo ilocucionário, uma fundação deontologica das instituições; preferindo a inspiração formalista da semântica clássica, mas no horizonte problemático e teórico de uma pragmática formal.

Habermas prefere falar de demandas de validade, e não de verdade (ou assertabiliy), ja que elas não serian formuláveis e possíveis fora das condições pragmáticas de relativização do significado do enunciado.

Quando a oferta enunciativa de um proponente passa a ser negada ou contestada por uma das partes envolvidas (oponente), as demandas de validade passam a ser tematizadas, e nesse momento, se passa da ação comunicativa ao plano reflexivo dos discursos. É importante lembrar que, para Habermas, uma argumentação é uma rede interativa de atos de fala, e não uma sequência monológica de textos e sentenças).

Maeve Cooke ressalta que a possibilidade de relativizar e de rejeitar as demandas de validade é o que caracteriza esse modo de comunicação (ver Cooke, 1998, p.11-12).

\subsection{Demandas de validade, argumentação e situação ideal de fala}

Para Habermas, seriam ao menos quatro as demandas de validade implícitas de uma ação comunicativa, que teriam um nexo comum na racionalidade: a inteligibilidade, a verdade ou objetividade, a correção normativa e a sinceridade. Uma comunicação orientada ao entendimento mútuo dos participantes, requer, para ser bem sucedida: a) que seja compreensível o sentido pragmático do ato ilocucionário assim como o conteúdo semântico do enunciado; b) que sejam 
realizáveis as expectativas existênciais ou as expectativas teóricas geradas pelos conteúdos proposicionais; c) que se reconheça a correção das normas; c) que seja aceita a sinceridade dos sujeitos envolvidos (ver, entre outros textos do autor, Habermas, 1998, p.142).

As demandas de validade estariam implícitas nos usos comunicativos cotidianos da linguagem. Quando essas demandas de validade são problematizadas, se mudaria o plano de uso da linguagem, passando para um domínio reflexivo em que aquelas normas implícitas são tematizadas, como objeto de contestação, e sujeitas a revisão, em deliberações coletivas, pelos participantes da ação comunicativa, dando-se inicio as lógicas argumentativas dos Discursos (Diskurs).

Habermas avança na reconstrução do que seriam os recursos de legitimação pós metafísicos, do agir comunicativo, num esforço permanente de elucidação.

Uma de suas apresentações mais esclarecedora para nossa proposta de análise, seria aquela onde aborda a estrutura da argumentação e a situação ideal de fala.

Para Maeve Cooke, alem de um plano inicial da ação comunicativa habitualizada e sem questionamento, e de um segundo nivel de reflexividade, que é o discurso, disponível em qualquer esfera de ação comunicativa, caberia agregar um terceiro nível de construção reflexiva de discursos deliberativos, próprio da tematização de demandas de validade no contexto de formas institucionalizadas e especializadas de argumentação (conforme Cooke,1997, 1998, 2000). A esse terceiro nivel de argumentação (pressuposto, mas não explicitado pelo autor), pertenceriam as controversias, os confrontos paradigmáticos, as demandas de justificação teórica dos conhecimentos científicos.

Habermas diferencia a estrutura da argumentação, na qual se apoiariam as decisões racionalmente motivadas acerca de pretensões de validade teóricas e práticas, e as propriedades formais dos discursos.

Discursos teóricos e discursos práticos teriam formas diferenciadas de argumentação. Discursos teóricos, são aqueles onde são problematizadas demandas de validade epistêmica, orientadas à objetividade e à verdade, e constituem processos de autorreflexão dos participantes, enquanto sujeitos de conhecimentos. Nos discursos práticos, são problematizadas as demandas de correção normativa, orientadas ao prosseguimento da interação; trata-se de processos argumentativos visando à concertação, e que encon- tram em molduras normativas formais e generalizadas, os recursos para a crítica e para o reconhecimento do que sejam, em cada caso, garantias argumentativas consistentes e capazes de justificar demandas de validade contestadas.

Sendo que uma ética teórica só poderia esclarecer pressuposições procedimentais, sem oferecer nenhum suporte a decisões de cunho normativo, as avaliações normativas resultariam do empreendimento em comum de Discursos práticos, entre os envolvidos em dissensos normativos.

Para Habermas um processo de progressão dos conhecimentos teóricos aconteceria pelos movimentos entre o conhecimento e o meta-conhecimento (ver Habermas, 1994c, p.151).

Habermas, em seus primeiros trabalhos sobre o tema, apresenta um esquema de degraus ou níveis de progressão, no que seriam etapas de radicalização dos discursos.

As dinâmicas progressivas de validação intersubjetiva de teorias, se iniciaria a partir do dissenso das partes envolvidas, pela passagem das afirmações problematizadas ao plano reflexivo em que são tematizadas as demandas de validade contestadas, no plano do Discurso (Diskurs). Num segundo passo, no caso do Discurso teórico, o proponente deverá ofertar ao oponente ao menos um argumento a favor da afirmação contestada. Neste caso, os argumentos apresentados deverão atender aos critérios de validade das explicações teóricas, que poderia acontecer a) pela explicação de fenômenos com a ajuda de regularidades observadas, hipóteses particulares ou teorias; b) pela explicação de enunciados teóricos e teorias, com o auxílio de outras teorias. Em qualquer caso, a oferta de garantias argumentativas teóricas, se manteria no sistema de linguagem do ponto de partida. É num passo ulterior que a resolução do dissenso levaria a mudar de sistema de linguagem ou a considerar e ponderar sistemas de linguagens alternativos.

A mudança da linguagem teórica produziria um novo deslocamento de nível discursivo, passando-se do discurso teórico a um um discurso meta-teórico, onde acontece a crítica do conhecimento, propriamente dita, e que toma como objeto de deliberação reflexiva as mudanças sistemáticas das linguagens de fundamentação.

O progresso do conhecimento acontece assim como crítica substancial das linguagens, porque somente a superação de linguagens e sistemas conceituais inadequados, permitiria que se configurasse um novo estado social dos conhecimentos. Habermas esclarece que por isso existiria uma conexão sistemática entre a Teoria das ciências e a História sistemática das ciências, já 
que as duas se apoiariam nas manifestações e mudanças dos sistemas (e textos) das linguagens científicas. Essa relação entre o estado da arte das teorias científicas e a história sistemática da ciência, vai fornecer, ao mesmo tempo, um subsídio argumentativo na elaboração de sua teoria da reconstrução (Honneth, 2009).

Esse quarto passo vai, porém, além das possibilidades de teorização, pela ruptura dos limites do discurso teórico, num movimento circular próprio das reconstruções racionais, já que a crítica do conhecimento requer uma certeza pública acerca de que deve valer como conhecimento (Habermas, 1994c, p. 151).

O movimento do conhecimento ao meta-conhecimento, seria assim um movimento constante de monitoramento, revisão e avaliação, com impacto em processos decisórios. Esses movimentos recursivos entre conhecimento e meta-conhecimento, gerariam a convergência das condições teóricas e prático-normativas dos processos de justificação, já que a medida do valor de um conhecimento se estabelece pela ponderação conjunta de valor daquilo que é o conhecido e do interesse e direção em função dos quais o conhecer, conhece seu objeto.

Ora, existiria também dinâmicas progressivas na constituição das linguagens normativas da ética e da política. A forma do discurso prático deve permitir também uma "progressiva radicalização" agora como autocompreensão reflexiva do sujeito agente situado em coletivos de ação.

O primeiro passo seria o movimento que leva de um mandato ou proibição contestados, que pertencem ao plano das ações, às recomendações ou advertências, que são objetos de discurso. $\mathrm{O}$ próximo passo, será oferecer argumentos que justifiquem as demandas de validade tematizadas dessas recomendações ou advertências, dentro da linguagem escolhida. Um passo além seria, de maneira equivalente ao que acontece nos discursos teóricos, a mudança do sistema de linguagem do ponto de partida ou a ponderação da adequação de sistemas de linguagem alternativos. Instaura-se então um plano metaético ou metapolítico (Habermas, 1994c, p. 152).

O último nível da radicalização progressiva do discurso prático, implica: 1) o transito em direção à reflexão sobre as relações de dependência entre as estruturas de nossas necessidades e o estado de nosso saber e nosso poder; 2) a disponibilidade das informações existentes acerca do factível e do que pode ser conseguido, em base das quais é possível chegar a um acordo na interpretação das necessidades; 3) o julgamento de valor das informações que serão importantes no futuro e as quais daremos tratamento preferencial; 4) relacionar a questão prática de definição de um regime preferencial de informação, com as prioridades a serem estabelecidas no fomento da ciência.

O ciclo progressivo dos discursos práticos teria assim como culminação o estabelecimento de um compromisso público e coletivo com uma política do conhecimento (Habermas, 1994a, p. 152).

Nesse ponto, se produziria a ruptura dos limites do discurso prático, pela vínculo irredutível entre que conhecimento devemos querer, questão ético-política do discurso prático, e a questão de que conhecimento podemos querer, questão teórica, de resolução empírica e metodológica, com referências de caráter local e histórico, que requer o conhecimento do estado atual do conhecimento, o que em sua máxima extensão, podemos supor, requer ponderar o sentido e direção dos sistemas das ciências na ordem mundial e contemporânea (Cif. Habermas, 1994c, p. 152).

A hipótese habermaseana de uma dupla ruptura de limites e o transito interdiscursivo dos discursos teóricos e práticos, não é alheia a sua reiteração dos atributos da razão comunicativa, adquiridos em processos de aprendizagem, ontogenético e filogenéticos, o que permite aos agentes da ação comunicativa passar de um modo a outro de discurso (teórico, prático); de uma categoria a outra das demandas de validade (objetividade, correção normativa, sinceridade), de uma atitude acerca do mundo a uma outra atitude (conforme pressuposições ontológicas do mundo natural, do mundo subjetivo e do mundo social).

A situação ideal de fala, ao mesmo tempo pressuposição justificada e premissa contrafactual, seria uma modelagem hipotética das condições formais do discurso. No seu texto Teorias de la Verdad (1994c), define uma situação ideal de fala como aquela em que as comunicações não são obstruidas nem por coações externas nem por constrangimentos que derivam dos proprios arranjos comunicativos, de modo de excluir toda distorção sistemática da comunicação (Habermas, 1994c, p. 157).

As situações ideias de fala estariam sujeitas ao cumprimento de condições iniciais triviais (condições de reciprocidade) e condições não triviais(condições de simetria); estas segundas, remetem de maneira indireta aos discursos, mais de maneira imediata à organização dos contextos de ação e inetração.

Seriam condições triviais ou de reciprocidade: 1) com respeito aos papéis de falante/ouvinte, emissor/receptor (iniciação de um ato de fala), todos 
os participantes de um discurso têm de ter a mesma oportunidade de realizas atos de fala comunicativos, iniciar discursos e dar-Ihe continuidade, mediante perguntas e respostas; 2) com respeito às modalidades dos jogos de linguagem, todos os participantes do discurso devem ter oportunidades simétricas desempenho das "oportunidades" pragmáticas de produção de sentido, tal como interpretar, afirmar, recomendar, explicar, justificar, rebater as demandas de validades em questão, de modo que todos os pontos de vistas relativos a aquilo que se problematiza, sejam expostos à tematização e a crítica (Habermas, 1994c, p. 153-154).

As condições não triviais, remetem diretamente as condições de constituição efetiva dos fóruns discursivos. Elas são: 1) a simetria expressiva, pela qual locutores que participam de uma interação comunicativa e reflexiva podem realizar atos de fala expressivos, expressar suas atitudes, sentimentos e desejos, o que é condição da sinceridade e transparência de suas identidades, para sim e para os outros (em Habermas, 1994c, p.153); e 2) a simetria da potência normativa, implica a reciprocidade completa de expectativas de comportamento, excluindo privilégios e exclusões, de modo que todos os participantes do discurso tenham oportunidade de realizar "atos de fala regulativos" que operem sobre a estruturação da própria situação discursiva da qual participam (Habermas, 1994c, p. 154; Benhabib, 1986).

\subsection{Entre a norma e a utopia}

À bifurcação da racionalidade, em Habermas, entre um uso estratégico da razão instrumental-funcional (relações assimetrias e sem reciprocidade entre os envolvidos na ação), e um uso comunicativo da razão (relações simétricas e recíprocas, visando ao entendimento mútuo), visa a substituir a unidimensionalidade negativa da racionalidade dos seus predecessores de Frankfurt, deixando em aberto outras possibilidades de análise para a sociologia e para a filosofia social.

Corresponde a essa bifurcação a diferenciação das possibilidades de um poder comunicacional, legítimo, sustentado por convicções compartilhadas, e um poder social, exercido por alguns em detrimento dos interesses e desejos de outros, visando a impor interesses não generalizáveis em programas de ação, de forma coativa, e por meios materiais ou simbólicos. (Habermas, 1994b, p.459, Dutra, 2006).

Sendo a linguagem tanto um lugar de entendimento como desentendimento, de solidariedade e violência, como as esferas virtualizadas dos
Discursos poderiam iniciar e radicalizar processos de progressão?

Habermas oferece um argumento a favor de sua construção teórica do conceito de Discurso e de sua modelização hipotética da situação ideal de fala, do ponto de vista da ética, mas que poderia aplicar-se tanto no contexto prático quanto no teórico: suas concepções, antes que como regras atuais de orientação dos comportamentos sociais, agem como provisão de recursos críticos para dar visibilidade aos interesses não generalizáveis que buscam impor-se como formas de exercício do poder social (ver Benhabib,1986b, p291)

As mobilizações sociais e os Conselhos de argumentação, seriam instancia de aprendizagem e de desempenho de algumas das possibilidade de radicalização progressiva da razão comunicativa. Como intersubjetividades vinculadas por um duplo compromisso, ilocucionário e social, ConseIhos ou fóruns de argumentação assumiriam funções exemplares na generalização possível de julgamentos normativos.

É o procedimento que pode fazer de um fórum ou colegiado o agente de atualização das potencialidades normativas de um uso público da razão.

Habermas (2002) destaca as implicações do caráter público de uma decisão avaliativa: a) rejeição de posições tecnocráticas, que reduziriam as escolhas políticas e decisões normativas a questões administrativas, as quais ficariam nas mãos dos especialistas; b) rejeição das posições do decisionismo, que considera que a perícia científico-administrativa nunca poderia eliminar a incumbência de uma escolha moral, nas mãos dos políticos.

\section{Foucault, o avesso de uma história da ciência}

Em Foucault, seria mais fácil entender sua identificação com as teorias críticas, que tratar de descrever seu posicionamento em torno as figuras modernas de legitimação ética e epistêmica, assim como o lócus e papel que atribui, em suas análises, aos processos de racionalização, como inovações modernas.

Foucault retoma em várias ocasiões a pergunta que incitara a reflexão de Kant, O Que São as Luzes? (Was ist Aufklarung?), e que retornaria no cenário contemporâneo como o mais atual dos passados, o melhor, como o passado que ainda não terminou (Foucault, 2006, 2008b). Pergunta que seria alavancada pela história da ciência na França e pela teoria crítica alemã, tratar-se-ia de 
examinar "uma razão que só tem efeito de libertação desde que ela consiga libertar-se de si mesma" (Foucault, 2008a, p. 357).

Entre os processos que levariam a essa retomada e atualização da pergunta, o primeiro seria "a importância assumida pela racionalidade científica e técnica no desenvolvimento das forças produtivas e no jogo das decisões políticas"; o segundo, a frustação das expectativas de progresso sustentada no potencial emancipatório do racionalismo, sendo que o exercício da racionalidade assume tanto a forma de despotismo como de esclarecimento; o terceiro, e o de maior generalidade, o de retorno do perguntar como pergunta de Ocidente acerca de seu lócus numa história civilizatória, antes que numa história da razão: perguntar em que se apoiam suas reivindicações de que sua cultura, sua ciência, sua organização social e sua racionalização tem uma validade universal (Foucault, 2008a, p. 357). Podemos pressupor que seu perguntar, que não se inclui nem na história da ciência liderada por Canguilhem (ainda que teria sido uma importante referência em sua formação), nem na crítica alemã, está porém e igualmente relacionado com os processos que tiveram como efeito a atualização da pergunta pela autocompreensão humana do presente.

Das investigações de Foucault, algumas das mais reconhecidas seriam aquelas que tratam das modalidades e exercício do poder na modernidade, e sua imersão numa multiplicidade de micro práticas. Para Fraser (1981), seu maior aporte estaria na apresentação de diferentes casos e evidencias empíricas do que há de entender-se como modos de exercício do poder, questionando abordagens anteriores equivocadas ou insuficientes para dar conta de sua complexidade: a) o poder é produtivo, antes que repressivo, o que desabilitaria muitas das estratégias promovidas como emancipatórias; b) o poder possui uma grande capilaridade, o que contradiz as concepções do poder centradas no Estado; c) o poder se exerce em e sobre as práticas, antes que sobre as crenças e os discursos, o que desativa, entre outros, muitos argumentos das teorias da ideologia (Fraser, 1981).

Seguindo aparentemente a estratégia de deixar em suspenso ou "colocar entre parêntesis" padrões normativos que permitissem diferenciar formas legítimas e ilegítimas poder, por um lado, obtém bons resultados, na medida que pode trazer a luz traços antes não perceptíveis ou negligenciados das figuras modernas do poder. Por outro lado, porém, esse mesmo procedimento de bracketing (Fraser, 1981) ou de ausência de algum sistema alternativo de escolhas normativas, deixaria em aberto muitos questionamentos acerca do sentido e direção de sua crítica. De maneira simplificada, poderíamos usar como exemplo suas análises das relações poder e saber, já que se não temos critérios ou atributos para diferenciar como e quando o saber é independente ou é totalmente subsumido pelo poder, não somente não poderíamos reconhecer ou ponderar as figuras relacionais que agregam os dois termos, mas nem sequer poderíamos relaciona-los. Essa mesma aparente suspensão de critérios normativos, por outro lado, parece contrapor o Foucault dos cursos e da escrita acadêmica com o ator engajado da sociedade civil francesa, um dos criadores do Grupo de informação sobre as prisões - GIS, que teria servido de inspiração a muitos outros grupos de defesa dos direitos humanos (3).

Uma visão mais abrangente de sua obra, permitiria, quiçá, identificar em seus trabalhos a reconstrução de recursos normativos que o aproximassem da linhagem europeia da teoria crítica. Após a publicação de seus cursos, onde os estudos do neoliberalismo, das novas figuras do mercado e da Biopolítica, atualizam o tratamento das questões de governamentalização da população e da vigência dos mecanismos de segurança, enxergamos novas perspectivas sobre seu posicionamento respeito aos macro- temas das esferas da filosofia, da ética e da política, que excedem, se bem não renegam, do prévio escopo e abrangência de uma "política da vida cotidiana" (expressão recuperada por Fraser, 1981, p. 272).

No processo de melhor entender esse cruzamento de perspectivas e outras pressuposições de relativismo epistemológico, rastrearemos rápida e seletivamente alguns dos textos de Foucault, cientes de que, em outros, algumas das afirmações por eles sustentadas podem ter sido replicadas, suavizadas, descartadas ou mesmo substituídas ou resignificadas, em sua múltipla, densa, sinuosa, mas sempre desafiante produção textual.

\subsection{As relações saber-poder: vigiar e punir}

Uma das relações saber-poder, analisadas por Foucault, seria a que acontece nas sociedades disciplinares, onde as tecnologias de monitoramento e produção de evidencias que são os exames, são duplamente produtivas: induzindo e formatando práticas, orientando-as em direção ao sucesso (resultados esperados) e, ao mesmo tempo, gerando um tipo de saber sobre as práticas monitoradas, que não pertencerá ao sujeito dessas práticas, mas aos agentes de sua indução e monitoramento: uma ação de conhecimento de segundo grau (pedagogia, medicina, 
estratégia militar) sobre um outro plano de ação, que podemos denominar um plano "primário".

No contexto do ensino-aprendizagem, o exame sistêmico gera "um campo de conhecimento sobre o aluno", a diferença de prova, que seria um atestado corporativo de perícia, ou da "obra prima", que autentifica o saber adquirido. Nas ações clínico-hospitalares, os exames e outros instrumentos administrativos, como os prontuários, geram um campo de conhecimentos diferenciado da prática clínica, dando à medicina sua chancela epistemológica. Desse modo, na relação clínica ou pedagógica se faz a passagem de um conhecimento para alguém que fará dele um usufruto (aluno, paciente), mas se retira desse alguém um saber, que é agora saber do especialista: do mestre, saber pedagógico; do médico e do hospital, saberes da medicina (Foucault, 1987, p. 166):

[...] A escola torna-se o local de elaboração da pedagogia. E do mesmo modo como o processo do exame hospitalar permitiu a liberação epistemológica da medicina, a era da escola "examinatória" marcou o início de uma pedagogia que funciona como ciência.

Caberia assim ao regime disciplinar uma primeira geração e agregação de conhecimentos especializados, em esferas institucionais formalizadas, onde os muitos (indivíduos e práticas), serão objeto de um saber sistemático, gerado por uns poucos bem equipados com procedimentos inovadores de registro, aprendizagem e monitoramento. Os nexos e fluxos entre o saber e o poder disciplinar, seriam estabelecidos com apoio de tecnologias aplicadas ao tratamento seletivo e homogeneizador da multiplicidade, mediações que Foucault denomina tecnologias de poder.

Um "poder de escrita" é constituído como uma peça essencial nas engrenagens da disciplina. Em muitos pontos, modela-se pelos métodos tradicionais da documentação administrativa, mas com técnicas particulares e inovações importantes. Umas se referem aos métodos de identificação, de assimilação, ou de descrição (Foucault, 1987, p. 168).

A escrita e a documentação seriam parte importante dos processos de organização da multiplicidade, permitindo equacionar os processos de "individuação descendente" e a agregação homogeneizadora das singularidades: se constituem assim as planilhas de salários, os inventários de prontuários médicos, os repositórios de fichas catalográficas que organizam coleções e acervos. As técnicas de objetivação e de registro permitem assim a individualização dos "casos" e a acumulação dos dados individuais em sistemas cumulativos, que permitiriam primeiro a organização dos agregados e posteriormente, um novo estrato de saberes e instrumentos de gestão.

As outras inovações da escrita disciplinar se referem à correlação desses elementos, à acumulação dos documentos, sua seriação, à organização de campos comparativos que permitam classificar, formar categorias, estabelecer médias, fixar normas (Foucault, 1987, p. 169).

Junto às fábricas, as escolas e os hospitais, os exércitos profissionais e os escritórios administrativos, estariam sendo formados os novos laboratórios e memórias objetivadas: neles eram sistematizados, ao mesmo tempo, os saberes especializados e os programas de ação que faziam possíveis os novos modos de formação e expropriação de excedentes: de trabalho e de conhecimentos, das disposições dos corpos e da normatização das práticas, dos dados e dos documentos. As inovações tecnológicas (de anotação, de registro, de constituição de processos, de colocação em colunas) precederiam e acompanhariam às inovações epistemológicas.

O nascimento das ciências do homem? Aparentemente ele deve ser procurado nesses arquivos de pouca glória onde foi elaborado o jogo moderno das coerções sobre os corpos, os gestos, os comportamentos (Foucault, 1987, p. 169).

Se antes o indivíduo comum estava "debaixo do limite da descrição", os regimes disciplinares tendem à descrição das existências reais, dos "muitos", dos $1+1+\ldots$, como um meio de monitoramento e de controle: "Não mais monumento para uma memória futura, mas documento para uma utilização eventual." (Foucault, 1987, p. 169). Foucault denomina a essa operação reorganizadora de padrões de identificação e e de memória, a "troca do eixo político de individualização".

Nas sociedades das quais o regime feudal seria um bom exemplo, a individuação é ascendente, acontece no topo da pirâmide dos privilégios, onde a heroificação se apoia tanto numa genealogia patrimonialista quanto nos relatos e manifestações de proezas que atestam a superioridade do indivíduo exemplar, e busca a perpetuação do monumento. $\mathrm{Na}$ sociedade disciplinar, aconteceria uma individuação descendente, de modo que os individualizados são os muitos, os $1+1+1$, objeto de observações antes que de comemorações, alinhados por comparações e não por genealogias, tendo então como meio de inscrição de suas identidades controláveis, sem perdida do anonimato, os documentos (o exame, o prontuário, a carteira de trabalho). No regime disciplinar, o que se destaca é o desvio (Foucault, 1987, p. 171): 
Num sistema de disciplina, a criança é mais individualizada que o adulto, o doente o é antes do homem são, o louco e delinquente mais que o normal e o não- delinquente.

Os dispositivos do regime disciplinar, montados no eixo da individuação descendente, visariam ao ordenamento produtivo da multiplicidade das crescentes populações urbanas, seja pela normalização institucional das práticas, seja pelos efeitos coativos dos sistemas de vigilância.

\subsection{Do código, da norma e da normalização}

Em muitos momentos, e sobretudo em seus últimos cursos, Foucault ordena, categoriza e embaralha três regimes de poder e os modos de subjetivação que caracterizariam a passagem da civilização ocidental pelos processos inovadores da modernidade: sociedades de soberania, sociedades disciplinares, sociedades dos mecanismos de segurança (ou, após Deleuze, sociedades de controle). Se existem algumas indicações de sequência, Foucault não deixa de enfatizar que existem tanto rupturas quanto justaposições entre os regimes de poder.

Portanto, você não tem uma série na qual os elementos vão se suceder, os que aparecem fazendo seus predecessores desaparecerem. Não há a era do legal, a era do disciplinar, a era da segurança (Foucault, 2008e, p. 11):

$[\ldots]$ o que vai mudar $[\ldots]$ é a dominante [...] o sistema de correlação entre os mecanismos jurídicolegais, os mecanismos disciplinares e os mecanismos de segurança .

Nos textos do curso de 1978, trabalha na reconstrução de uma família de conceitos emparentados com a categoria de regra/norma, a saber: códigos, normação e normalização.

Foucault remete a Kelsen, quem estabelece uma relação fundamental entre a lei e a norma, sendo que todo sistema legal se relaciona a um sistema de normas. Para Foucault, há uma normatividade intrínseca à lei, mas o que trata de colocar em evidencia é que, quiçá a contramão da lei, se desenvolvem as técnicas de normalização (Foucault, 2008e, p. 74) .

Em cada regime de poder, mudaria o princípio organizador da matriz reguladora das relações sociais: se na sociedade disciplinar predominam as tecnologias formativas e de vigilância, orientadas aos processos individuação descendente, nas sociedades dos mecanismos de segurança, a matriz organizacional vai desenvolver-se em torno do conceito de população e dos modos de sua governamentalização.

Por definição, a população é algo opaco, difuso, que requer para sua construção novas técnicas de abstração e modelização. Seria sob os mecanismos do biopoder, que a figura abstrata da população ganharia a contextura naturalista da espécie. Na aula do 11 de janeiro de 1978, parte de estabelecer o ponto de vista com que abordará suas lições desse ano, o estudo do biopoder, que seria (Foucault, 2008e, p. 3):

[...] o conjunto dos mecanismos pelos quais aquilo que, na espécie humana, constitui suas características biológicas fundamentais vai poder entrar numa política, numa estratégia política, numa estratégia geral de poder. ...o que chamo de biopoder [...consiste em...] um certo número de proposições...no sentido de indicações de opção; não são nem princípios, nem regras, nem teoremas [...]

Para melhor entender essas dinâmicas das inovações incrementais da modernidade, podemos deter-nos em três daquelas categorias axiais dos regimes de poder: códigos, normação e normalização:

a) Os Sistemas legais operam através de códigos jurídicos, constituídos por padrões binários que estabelecem e o permitido e o proibido, junto à vinculação obrigatória entre a ação proibida e sua punição. Nas sociedades de soberania, onde o exercício do poder segue aquela lógica binária, o código determina o proibido, enquanto o permitido é tudo o que é assunto de indeterminação (Foucault, 2008e, p. 8 ss., p. 61).

b) Os mecanismos disciplinares visam à normalização da ação, entendida como o estabelecimento de um padrão de práticas corretas, enquadrando-as por mecanismos de vigilância e correção. Foucault denomina a essa forma de normalização, normação, destacando a centralidade da norma pré-estabelecida. Existiria sempre uma dinâmica entre a descrição funcional das práticas e a definição da norma. Para Foucault, o regime disciplinar atua pela adoção de práticas exemplares, das crianças que aprendem melhor, do meIhor modo de carregar um fuzil, do operário que mostra mais aptidão em realizar uma tarefa. A partir da identificação e classificação desses componentes funcionais, escolhido por sua relação com um objetivo estabelecido, vão ser elaborados os procedimentos de treinamento, a demarcação dos aptos e os inaptos, as categorias do normal e o anormal. Para Foucault (2008e, p.75), "[...] o que é fundamental e primeiro na normalização disciplinar [...] é a norma".

c) Os dispositivos de segurança instauram novos mecanismos reguladores, que Foucault denomina normalização (Foucault, 2008e, p. 76 ss.). $O$ regime dos dispositivos de segurança seria aquele em que a natureza ingressa no campo do poder; a população será assim naturalizada como espécie, e não descrita a partir de alguma 
noção jurídica ou política, como quando se fala do sujeito de direitos. Ao mesmo tempo em que uma biologia ontológica reformula os processos de subjetivação, a população emerge agora nas superfícies discursivas como o público, clientela dos mercados econômicos e políticos, a serem auscultados e decifrados pelas pesquisas de opinião e os perfis de consumidores. Defrontados com uma realidade de rápidas transformações, os regimes dos dispositivos de segurança estão abertos a multiplicidade e diversidade do real, que eles capturam como dados. Os conhecimentos são definidos pelas metrias e pelos cálculos, ja que se trabalha com variáveis e valores que mudam muito rapidamente, e o que se busca é estabelecer (e estabilizar no possível), faixas aceitaveis de oscilação. $E$ isso aconteceria, por exemplo, com a fome e a segurança alimentar, o controle epidemiológico das variáveis da saúde. A passagem do exame à medida, será tambem a passagem das semânticas descritivas ao cálculo, os modelos e a simulação, substituindo as linguagens naturais pelas matemáticas e as lógicas das probabilidades.

\subsection{Além da verdade e da mentira: o regime de veridição}

Nas sociedades modernas, a partir do século $\mathrm{XVIII}$, reconfiguradas as relações locais de trocas por estratégias concorrenciais, o mercado passa a ser o grande dispositivo de veridição econômica (preços, salários) e por extensão, de qualquer outro dos programas de ação e resultados políticos e sociais. Isto não significaria que a partir da formação de um discurso científico e teórico, a economia política, sobre o papel e as regras das relações econômicas, o Estado e os governantes tivessem adotado e generalizado tal regime de veridição, pela força de convicção dessa teoria científica.

Foucault, em seu curso sobre Biopolítica (19781979), ao mesmo tempo em que ilustra seu posicionamento nos processos avaliativos e decisórios das sociedades liberais e neoliberais, faz do mercado um caso exemplar para generalizar aquilo que está chamando de regime de veridição. O que se pode afirmar acerca do mercado e da Economia, poderia afirmar-se de modo semeIhante, por exemplo, a respeito das instituições de encerramento e da Psiquiatria, ou acerca das escolas e da Pedagogia. Todas essas questões e abordagens formariam parte do que entende por uma história da verdade, que é mais propriamente dito, a história dos regimes de veridição (Foucault 2008d, p. 48-49):

[...] Tratar-se-ia da genealogia de regimes veridicionais...de fato, o regime de veridição não é uma certa lei de verdade, [mas sim] o conjunto das regras que permitem estabelecer, a propósito de um discurso dado, quais os enunciados poderão ser caracterizados, nele, como verdadeiros ou falsos.

Não se trata assim de uma história exclusivamente da verdade nem de uma história do erro; não se trata da crítica aos excessos da racionalidade europeia (tema do romanticismo e de Frankfurt), porque a razão é opressiva, mas a "falta de razão" é igualmente opressiva; e se a verdade pode ser opressiva, mentiras e erros também constituem abusos do poder (ver Foucault 2008d, p. 49-50).

A crítica que lhes proponho consiste em determinar em que condições e com quais efeitos se exerce uma veridição, isto é, mais uma vez, um tipo de formulação do âmbito de certas regras de verificação e falsificação. ...vocês veem que o problema não consistiria em dizer, por tanto: vejam como a psiquiatria é opressiva, porque é falsa. Não consistiria nem mesmo em ser um pouco mais sofisticado e dizer: olhem como ela é opressiva, já que é verdadeira (Foucault, 2008d, p. 50).

A crítica, para ter alcance político, não deveria visar a gênese das verdades ou a memória dos erros, o que importa é determinar que regime de veridição foi instaurado num determinado momento- isso é o que permitirá afirmar que no século XIX os médicos teriam afirmado tolices sobre o sexo. O regime de veridição Ihes permitiu afirmar coisas que hoje sabemos que não seriam assim (Foucault, 2008d, p. 50).

È precisamente nesse ponto em que a análise histórica pode ter um alcance político. Não é uma história do verdadeiro, não é uma história do falso: a história da veridição é que tem importância politicamente. Era isso o que eu queria Ihes dizer, da conexão de um regime de verdade à prática governamental (Foucault, 2008d, p. 51).

Foucault diferencia com clareza a razão dos modos da racionalidade, sustentando que poderia falar-se não de uma bifurcação, mas de plurais bifurcações da razão, de sua ramificação abundante, descartando a bifurcação Habermaseana numa razão instrumental-funcional e uma razão comunicativa. Distanciando-se de seu horizonte inicial, fenomenológico, afirma que a bifurcação não aconteceria num único ponto do tempo nem numa única instancia transcendental (Foucault 2008c, p. 317-318):

[...] penso de fato que há uma autocriação da razão e, por isso, o que tento analisar são as formas da racionalidade: diferentes instaurações, diferentes criações, diferentes modificações pelas quais as racionalidades se engendram umas às outras, se opõem e se perseguem umas às outras, sem que, no entanto, se possa assinalar um momento em que se teria passado da racionalidade à irracionalidade. 
Nas entrelinhas, nos parece que Foucault está cotejando suas escolhas teóricas ora com a história das ciências, que seria uma parte decisiva da história das racionalidades, ora com os herdeiros da crítica de Frankfurt.

Logo, os regimes de veridição, antes que insumo de uma história das racionalidades ou das metodologias de sua reconstrução, funcionam como ferramenta heurística de um observatório do devir em aberto dos modos da autocompreensão humana, problematizando "[...] a que preço o sujeito pode dizer a verdade sobre si mesmo?" (Foucault, 2008c, p. 318). "O que me interessou, partindo do quadro geral evocado [...], eram justamente as formas de racionalidade que o sujeito humano aplicava a si mesmo." (Foucault, 2008c, p. 319).

Neste ponto, pode deixar de preocupar-nos a sistematicidade ou falta de sistematicidade das obras de Foucault. Seu texto se coloca sempre em algum momento da história da autocompreensão humana que não tem data antecipada de fechamento.

Suas grandes categorias analíticas (soberania, disciplina, segurança; código/lei, norma/modelo, normalização/cálculo), poderiam entender-se como recursos expositivos dos resultados de um trabalho de pesquisa que humana e temporalmente tem vários momentos conclusivos, como integrante de ciclos investigativos, mas que não pode oferecer, por convicção, uma formulação final, definitiva. Cada vez que se fecham, eles abrem, de fato, novos ciclos empírico-narrativos.

Não admite assim a identificação da razão com as aventuras das formas de racionalidade dominantes nos tipos de saber, nas formas técnicas e nas modalidades de governo e de dominação, objetos plurais da crítica ou da história: figuras da racionalidade podem surgir e desaparecer, mas razão não é por isso derrocada, porque 'razão' designa aquilo a partir do qual "outras formas de racionalidade se criam, sem cessar" (Foucault, 2008c, p. 324).

O autor nunca terá a última palavra, ele sempre faz sombra naquilo que ilumina.

\section{As teorias críticas, as ciências e os estudos da informação}

$\mathrm{Na}$ releitura seletiva (e parcial) de dois autores, nos que buscamos muitas vezes uma interlocução esclarecedora, tratamos de colocar em evidência como, antecipando-se à ou em consequência dos novos movimentos de redistribuição dos espaços paradigmáticos da produção científica, constroem um plano investigativo meta-normativo, onde revisam as possibilidades de uma crítica política que reúna questões epistemológicas, éticas e políticas.

Não ignoramos os aportes de Foucault as ciências em suas contexturas específicas e em sua temporalidade, especialmente nas ciências humanas e sociais e posteriormente nas ciências biológicas e naturais. Interessava, a efeitos da leitura agora encaminhada, reconhecer onde situava o plano de discernimento em que se pode lidar com os signos trocados dos valores, os jogos camuflados da razão e a racionalização, a hora em que as coisas mudam de lugar.

Foucault nos coloca nesse plano meta-normativo ao trabalhar com os regimes de veridição, plano no qual fica claro que o poder se exerce tanto no que se reconhece como verdadeiro como no que se descarta, como falso.

$\mathrm{Na}$ mesma direção, diríamos que a inserção da teoria da ação comunicativa no espaço acadêmico da América Latina, e especificamente nos estudos da informação e a documentação, não parece surgir de expectativas acerca da influência reformadora de suas idealizações normativas nem do efeito procedimental de suas lógicas argumentativas, como capazes de exercer algum estímulo motivador em contextos acionais reais. Acompanhando quiçá uma expectativa de seu autor, as matrizes normativas e formais de Habermas, que para Benhabib (1985), operam como uma dobradiça entre a norma e a utopia, tem sido apropriadas, muitas vezes, por ter efeitos heurísticos na iluminação de zonas opacificadas da história e da memória individual e coletiva: seja em situações de problemas onde os traços débeis de direitos subvertidos ou de necessidades, identidades e memorias apagadas, dificultam tanto a análise e reconhecimento de perdas, como a lembrança e socialização das evidencias de sucessos alcançados; seja em situações em que é necessário ponderar e redefinir sistemas de avaliação e procedimentos de tomada de decisão; seja quando, nos espaços públicos, se trate de ativar os ciclos recursivos entre os Discursos teóricos, os Discursos práticos e o estado das necessidades interpretadas.

Cabe perguntar, agora, de que modo a informação e a documentação estão fazendo a passagem dos ciclos de produção do discurso científico, para analisar os movimentos recursivos da informação e da documentação entre conhecimento e o meta- conhecimento, entre as questões morais e os fóruns híbridos epistêmicoético-políticos. 


\section{Notas}

(1) Sendo que o termo Diskurs, de Habermas, é de difícil tradução, por sua referencia a processos deliberativos, optamos por colocar o termo de sua tradução em maiúscula, Discurso, nos contextos em que achamos importante sinalizar sua diferença com o uso do termo em outras línguas e por outros autores.

(2) Numa nota da edição inglesa de 1979, Habermas esclarece; "Até aqui, o termo "pragmática" referia-se à análise de determinados contextos de uso da linguagem e não à reconstrução das características universais desse mesmo uso ... Para assinalar esse contraste, criámos uma distinção entre pragmática "empírica" e "universal", que, com tudo, atualmente já não nos satisfaz: o termo "pragmática formal" -enquanto extensão da "semântica formal", seria mais adequado." (Habermas, 1998, p. 92, Nota 1).

(3) Convidado a participar de uma Comissão de Inquérito, sobre as prisões, Foucault propõe a formação de um grupo de informação, o GIP, Grupo de Informação sobre as Prisões, visando a mobilização coletiva e ao engajamento de grupos profissionais específicos; o GIP daria origem a muitos outros grupos de escopo e características semelhantes, como o GIS, Grupo de Informação sobre a saúde e o GIA, Grupo de Informação sobre os asilos (Foucault, 2006, p.1).

\section{Referências}

Benhabib, S. (1986). Critique, Norm and Utopia. A Study of the Foundations of Critical Theory. New York, Columbia University Press, 1986.

Capurro, R. (2004). Ethics between law and public policy. // Journal of International Biotechnology Law.1:2, p. 62-66.

Cooke, M, (1997). Language and Reason. A Study of Habermas's Pragmatics. Massachusetts, MIT Pres $\left(1^{\text {a }}\right.$ Ed. 1994).

Cooke, M. (1998) Introduction. // Habermas, J.; Cooke, M. On the pragmatics of communication. MIT Press.

Cooke, M. (2011).Pragmatics in Habermas' Critical Social Theory. // Bublitz, W.; Norrick:R. (eds.). Foundations of pragmatics. Walter de Gruyter. 289-312.

Dutra, D. J. V. (2006). Da função da sociedade civil em Hegel e Habermas. // Utopía y praxis Latinoamericana.11:35.

Falcon-Lang, H. (2011). Antropoceno: podríamos estar en nueva era geológica por cambio climático. // BBC, 11 de mayo de 2011. http://www.bbc.com/mundo/noticias/2011/05/110511_nueva_era_geologica_antropoceno Ih.shtml.

Foucault, M. (1987). Vigiar e punir. Nascimento da prisão. Petrópolis, Vozes.

Foucault, M. (2006). Ditos e escritos, volume IV: Estratégia, Poder-Saber. Rio de Janeiro: Forense Universitária.

Foucault, M. (2008a). A vida: a experiência e a ciência. // Foucault, M. Ditos \& Escritos. Arqueologia das Ciências e História dos Sistemas de Pensamento. Vol.ll. Rio de Janeiro: Forense Universitária. 352-366.

Foucault, M. (2008b). O que são as Luzes? // Foucault, M. Ditos \& Escritos. Arqueologia das Ciências e História dos Sistemas de Pensamento. Vol.II. Rio de Janeiro, Forense Universitária. P 352-366.

Foucault, M. (2008c). Estruturalismo e pós-estruturalismo. // Foucault, M. Ditos \& Escritos. Arqueologia das Ciências e História dos Sistemas de Pensamento. Vol.Il. Rio de Janeiro: Forense Universitária. 307-334.
Foucault, M. (2008d). Nascimento da Biopolítica. São Paulo: Martin Fontes, 2008.

Foucault, M.(2008e). Segurança, território e população. São Paulo: Martin Fontes.

Foucault, M. (2012). Verdade, poder e Si mesmo. // Foucault, M. Ditos e escritos, volume V: ética, sexualidade, política. Rio de Janeiro: Forense Universitária.

Floridi, L. (2004). Informational realism. Conferences // Research and Practice in Information Technology. 37. http://crpit.com/confpapers/CRPITV37Floridi.pdf.

Fraser:(1981). Foucault on Modern Power: Empirical Insights and Normative Confusions. // International (PRAXIS International): 3, 272-287. http://www.ceeol.com.

González de Gomez, M. N. (1993). Da representação do conhecimento ao conhecimento da representação. I/ Ciência da Informação. 22:3, 217-222.

Habermas, J. (1988). Actions, speech Acts, Linguistically Mediated Interactions, and the Lifeworld. // On the Pragmatic of Communication. Cambridge, Massachusetts, MIT Press.

Habermas, J. (1994a), Que significa pragmática universal. // Habermas, J. Teoría de la acción comunicativa: complementos y estudios previos. Madrid, Catedra, 1994. (1 ${ }^{\mathrm{a}}$. Edição, 1984).

Habermas, J. (1994b). Réplica a objeciones (1980) // Habermas, J. Teoría de la acción comunicativa: complementos y estudios previos. Madrid, Catedra. (1'a. Edição, 1984).

Habermas, J. (1996, 1998). Some Further Clarifications of the Concept of Communicative Rationality. // On the Pragmatic of Communication. Cambridge, Massachusetts, MIT Press.

Habermas, J. (1997). Direito e democracia: entre facticidade e validade. Rio de Janeiro: Tempo Brasileiro.1.

Habermas, J. (1998). What is Universal Pragmatic? // On the Pragmatic of Communication. Cambridge, Massachusetts, MIT Press,

Honneth, A. (2009). Reconstructive social criticism with a genealogical proviso: On the idea of 'critique' in the Frankfurt School. // Pathologies of reason, 43-53.

Jasanoff, S. (1987). Contested boundaries in policy-relevant science. // Social Studies of Science.17:2, 195-230.

Kohn, E. (2015). Anthropology of Ontologies.// Annual Review of Anthropology. 44:1.

Latour, B. (2014). Anthropology at the time of the Anthropocene-A personal view of what is to be studied. // Distinguished lecture delivered at the American Anthropological Association annual meeting, Washington.

Simons, P. (2004). Criticism, Renewal and the Future of Metaphysics. // Richmond Journal of Philosophy, 6, 1-9.

Smith, B. (2003). Ontology. // Floridi L. (ed). Blackwell Guide to the Philosophy of Computing and Information. Blackwell, Oxford, 155-166.

Steffen, W.; et al. (2015a). Planetary Boundaries: Guiding Human Development on a Changing Planet. // Science.347, 736-46.

Viveiro de Castro, E. (2012). Modos de Existência. // Encontro Simondon, $2012 . \quad$ Video-conferencia. https://www.youtube.com/watch?v=xeiVzUIAlzs (evento organizado pelos grupos Medialab/UFRJ, LEIC/UFRJ e GeACT).

Enviado: 2015-07-28. Segunda versión: 2015-0Aceptado: 2013-0-. 